Palabra Clave (La Plata), octubre 2017, vol. 7, n 1, e040. ISSN 1853-9912

Universidad Nacional de La Plata.

Facultad de Humanidades y Ciencias de la Educación.

Departamento de Bibliotecología

\title{
Metadatos de accesibilidad en recursos educativos: análisis y propuesta
}

\section{Accessibility metadata on educational resources: Analysis and proposal}

\section{Silvana Temesio Vizoso *}

* Universidad de la República. Facultad de Información y Comunicación. Instituto de Información, Uruguay I silvana.temesio@fic.edu.uy

\section{PALABRAS CLAVE}

Metadatos

Accesibilidad

Recursos educativos
KEYWORDS

Metadata

Accesibility

Educational resources

\section{RESUMEN}

El trabajo analiza el papel de los metadatos de accesibilidad de los recursos educativos en los entornos virtuales de aprendizaje como un elemento de importancia para favorecer la educación inclusiva. Se estudia el modelo conceptual de la IMS Global Learning Consortium que incluye los perfiles de los estudiantes (PNP) y los recursos educativos (DRD). Se analiza el esquema LOM, su perfil LOM-ES y también la propuesta OBAA. A partir de este análisis se hace una propuesta de un conjunto de metadatos mínimos y se presenta un prototipo para el entorno virtual MOODLE. El eje de la propuesta es la concepción de la accesibilidad como una construcción colaborativa en la que a partir de la participación se va propiciando un proceso de reutilización y adaptación, en particular en los aspectos de accesibilidad.

\section{ABSTRACT}

The paper analyzes the role of accessibility metadata of educational resources in virtual learning environments as an important element to promote inclusive education. We study the conceptual model of the IMS Global Learning Consortium with student profiles (PNP) and educational resources (DRD). We analyze the LOM scheme, the LOM-ES profile and the OBAA proposal. From this analysis a proposal of a set of minimum metadata is made and a prototype is presented for the virtual environment MOODLE. The core of the proposal is the conception of accessibility as a collaborative construction in which, from the participation, a process of reuse and adaptation is favored, particularly in the aspects of accessibility.

Recibido: 2 de abril de 2017 | Aceptado: 25 de septiembre de 2017 | Publicado: 9 de octubre de 2017 


\section{Introducción}

Los recursos educativos dispuestos en repositorios tienen los metadatos explícitos, y es a través de éstos que se opera la búsqueda en el sitio; así es posible recuperar el recurso adecuado a una necesidad específica. Cuanto más detallada sea la catalogación del recurso, mayores serán las posibilidades de encontrar los recursos apropiados. Sin embargo, esto tiene su contracara, ya que aportar metadatos es una tarea especializada que insume un esfuerzo de consideración.

En los entornos virtuales de aprendizaje, los metadatos de recursos educativos están embebidos en el diseño de base de datos de la aplicación de entorno virtual, y son funcionales a las prestaciones que ofrece el mismo.

No obstante, los recursos educativos fluyen desde los repositorios a los entornos virtuales y viceversa, son transformados, adaptados, mejorados y vuelven a incorporarse a estos tránsitos una y otra vez.

El desafío es entonces encontrar un marco de interoperabilidad que habilite estos trayectos y logre vincular este ecosistema. Ese marco se sustenta en un conjunto de metadatos que pueda ser adoptado en forma consensuada en ambos sitios, y que constituya un núcleo mínimo en el cual estén considerados criterios de accesibilidad prácticos.

Los metadatos de mayor importancia para recursos educativos son LOM (LOM-ES, y en particular el anexo VII que toma los aspectos de accesibilidad) y OBAA (Objetos de aprendizaje Basados en Agentes), que es un esquema de metadatos de amplio uso en Brasil.

El modelo conceptual IMS analiza en forma general el tema de la accesibilidad y constituye un aporte relevante que también es considerado.

El núcleo de metadatos propuesto se puede mapear en los distintos esquemas mencionados y se incorpora a procesos que sufren los REA en los entornos virtuales, articulando la interoperabilidad con los repositorios.

La propuesta se plasma en un prototipo para el entorno virtual Moodle que se comenta en la última sección.

\section{Accesibilidad en IMS}

El IMS Global Learning Consortium (IMS GLC) es un consorcio formado por organizaciones del campo de la educación y las TIC que desarrolla especificaciones abiertas en este ámbito, con énfasis en la innovación digital educativa. Las recomendaciones de IMS han sido adoptadas por Universidades en todo el mundo, así como por centros educativos en general y también empresas. IMS analiza el impacto de la tecnología en la educación, brindando especificaciones y modelos conceptuales de los procesos educativos con el abordaje de la informatización en lo educativo (IEEE Standard for Learning Object Metadata, 2002; IMS Acces for all metadata Guide, 2004; IMS Access for all metadata Information Model, 2004; IMS Global Access for all, 2012; IMS Learning Design Specification, 2003; IMS Learning Resource Metadata specification, 2006). 
Como señalan Hilera González y Hoya Marín (2010), el objetivo es que, a partir de las especificaciones propuestas, se consiga la interoperabilidad de aplicaciones y servicios en la enseñanza electrónica para que los autores de contenidos y de entornos puedan trabajar conjuntamente.

La IMS Global Learning Consortium, aunque no es un organismo normalizador formal, es una fuente de estudio muy relevante en estos temas. La visión que aporta respecto a la accesibilidad es más amplia que la tradicional. Define la accesibilidad como una relación entre las necesidades de un estudiante y la oferta educativa. No se habla entonces de una diversidad o incapacidad, sino de aparear perfiles de necesidades con un recurso educativo que tenga adecuación a esas necesidades. La accesibilidad sería la habilidad del entorno de aprendizaje (respecto a la presentación, los métodos de control, la modalidad de acceso o los soportes del estudiante) para ajustarse a las necesidades de los estudiantes, ofreciendo actividades y contenidos alternativos pero equivalentes. Las necesidades y preferencias de los estudiantes pueden surgir del contexto en que se encuentran, las herramientas disponibles, su entorno o de una disfunción en el sentido tradicional.

Los sistemas accesibles adecúan la interface del usuario del entorno de aprendizaje, localizan recursos requeridos y ajustan las propiedades de los recursos para concordar con las necesidades o preferencias del estudiante.

Los entornos virtuales deben ofrecer un servicio inclusivo y personalizado considerando las necesidades y preferencias de cada alumno. Esto involucra transformaciones en la forma en que se planifican, ejecutan y evalúan los cursos y programas formativos con calidad y accesibilidad. En ese sentido, la Guía del Proyecto ESVIAL (2013) es un modelo de transformación y una propuesta de buenas prácticas. También es necesario que los entornos virtuales cuenten con artefactos que puedan articular esta praxis en los diseños instruccionales, los objetos de aprendizaje y la ejecución formativa concreta. Los aspectos de accesibilidad tienen que ser contemplados para que se pueda establecer una concordancia entre las particularidades del recurso educativo y las necesidades del estudiante.

IMS establece una doble perspectiva, la del usuario y la del recurso educativo. A partir de las necesidades del usuario y las especificaciones del recurso se realiza un encuentro para determinar la alineación del recurso con las necesidades del usuario y, en caso de no coincidir, la necesidad de realizar adaptaciones.

Por un lado existe una especificación PNP (Personal Needs Preferences; IMS Digital Personal Needs and Preferences, 2012) que establece un perfil de preferencias del usuario del entorno virtual de aprendizaje. Al ingresar a un entorno virtual de aprendizaje el usuario elije el perfil de preferencias que desee, y en este perfil de preferencias se establece el "Modo de acceso". Este modo de acceso podría definirse como el sistema sensorial o facultad cognitiva a través de la cual una persona puede procesar o percibir información. El modo de acceso puede tener los siguientes valores: textual, visual, auditivo o táctil.

El recurso a su vez tiene una descripción DRD (Digital Resource Description; IMS Digital Resource Descripcion Specification, 2012) que establece el modo de acceso que tiene el 
recurso.

En la Figura 1 se especifica el dominio en que mapea el modo de acceso: textual, visual, auditivo y táctil. El valor textual entiende texto como texto que es legible (no imagen), que puede ser percibido por un ciego a través de un lector de pantalla.

El otro concepto que maneja este modelo conceptual es el refinamiento. Un concepto puede tener mayor granularidad y ese nivel de detalle se considera un refinamiento. En la Figura 1 también se muestran los refinamientos del concepto visual: color, posición, orientación, tamaño del ítem. Si color es un refinamiento de visual, entonces color es más preciso o más especializado que visual. Si se trata de una imagen (visual), pero la imagen hace uso semántico del color (color), las personas que no perciben bien los colores tendrán dificultad en percibir el mensaje del recurso.

El modo de acceso visual significa que es necesaria la vista para aprehenderlo. Este elemento puede ser refinado para una necesidad más ajustada (como por ejemplo la baja visión) en la cual se determina que es necesario especificar el tamaño del elemento visual, que es un refinamiento de la característica que sigue estando incluida en el modo de acceso visual.

El modo de acceso está presente tanto en la especificación de las necesidades o preferencias del estudiante (PNP), como en la descripción de los recursos digitales (DRD). De esta forma, de la contrastación de las necesidades del estudiante y las características del recurso en base a un patrón común, surge si el recurso cumple con las necesidades del estudiante o es necesario realizar adaptaciones al recurso para que las cumpla.

Figura 1. Conceptos sobre el modo de acceso

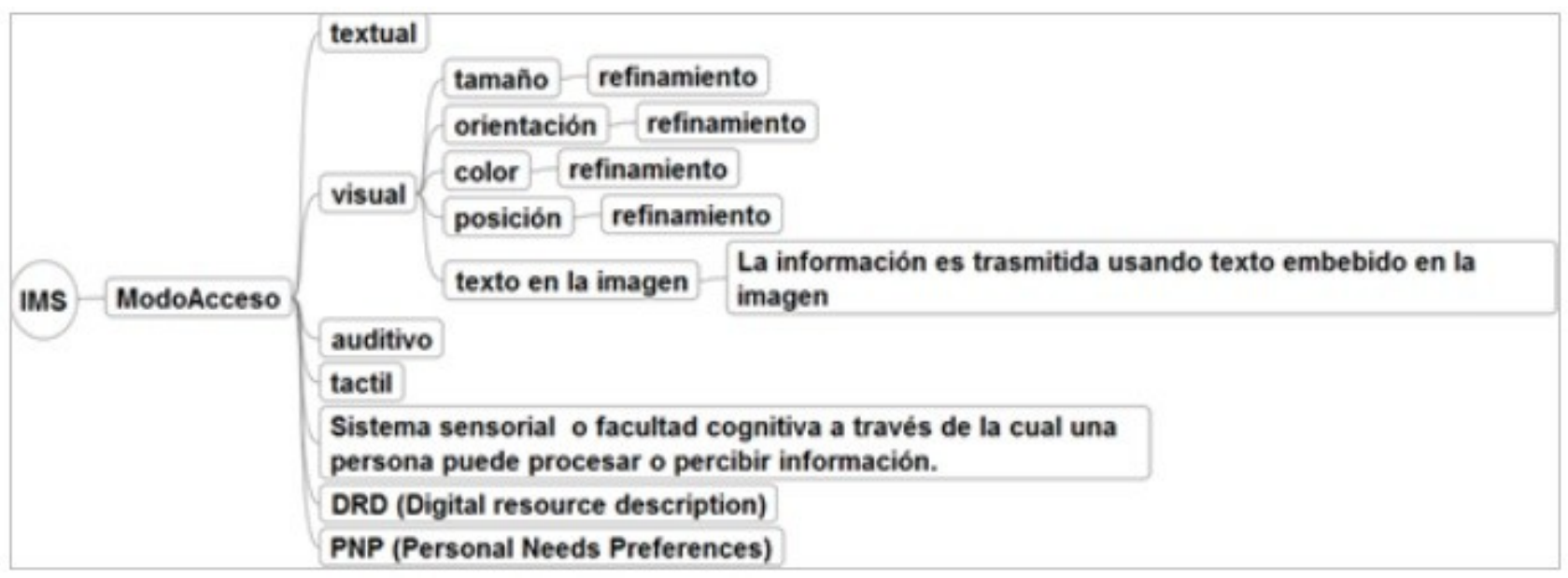

Fuente: Elaboración propia

Una persona ciega o con baja visión pondrá dentro del perfil de sus preferencias el modo texto en el entendido que puede acceder a un recurso digital que sea un texto. A su vez, un recurso digital que sea texto, pero cuyo formato sea una imagen, no cumplirá el modo de acceso texto ya que la información es trasmitida en un texto embebido en la imagen y su modo de acceso será visual. 
Al analizar el modo de acceso es interesante tomar en cuenta la clasificación de los estilos de aprendizaje que hacen Felder y Silverman (1988):

- Activo/reflexivo

- Visual/verbal

- Sensitivo/Intuitivo

- Secuencial/Global

La categoría visual/verbal corresponde a preferencias por imágenes/texto-audio. En este sentido se puede mapear el modo de acceso por una preferencia no solamente de accesibilidad sino por estilo de aprendizaje en esta categoría, lo cual podría resultar de utilidad para trabajar el formato de los contenidos del curso en otros aspectos que no son la accesibilidad. Correspondería explorar cómo gestionarlo, si en forma conjunta (correlacionada) o divergente.

Felder y Silverman (1988) reflexionan sobre esta dimensión:

La información visual claramente incluye dibujos, diagramas, gráficas, animaciones, etc., la información auditiva claramente incluye palabras habladas y otros sonidos. El medio de trasmisión de información que no está claro es la prosa escrita. Se percibe visualmente y por tanto obviamente no puede ser categorizada como auditiva, pero es también un error incluirla en la categoría visual como si fuera equivalente a un dibujo en cuanto a la trasmisión de información. Los científicos que estudian la cognición han establecido que nuestro cerebro generalmente convierte las palabras escritas en su equivalente hablado y las procesan de la misma manera en que procesan la palabra hablada. La palabra escrita por tanto no es equivalente a la verdadera información visual: para un aprendiz visual, una imagen vale más que mil palabras, ya sean escritas o pronunciadas. El plantear el estilo de aprendizaje visual/verbal resuelve este problema permitiendo que las palabras escritas o habladas se incluyan en la misma categoría (verbal). (1988, p.2., traducción propia)

Otra manera de aproximarse a estos conceptos es mirarlos desde otra óptica, desde el acceso y las necesidades específicas. Cuando existen dificultades visuales y nos enfrentamos a recursos auditivos éstos no requerirán ajustes. Si es un recurso visual habrá que analizar las distintas situaciones. Si es una imagen quieta como foto, pintura, etc. el recurso precisará de una adaptación. Si se trata de un texto legible, a través de una tecnología asistiva como puede ser un lector de pantalla, se podrá acceder al recurso y no requerirá adaptaciones. En cambio, si se trata de texto en formato imagen, para que sea accesible deberá pasar por un proceso de reconocimiento de caracteres (OCR) para convertirse en texto legible. En definitiva, salvo el caso del texto legible (que IMS refiere como modo de acceso texto) las otras situaciones requerirán adaptaciones para asegurar el acceso. Esto se esquematiza en la Figura 2. 


\section{Figura 2. Dificultades visuales}

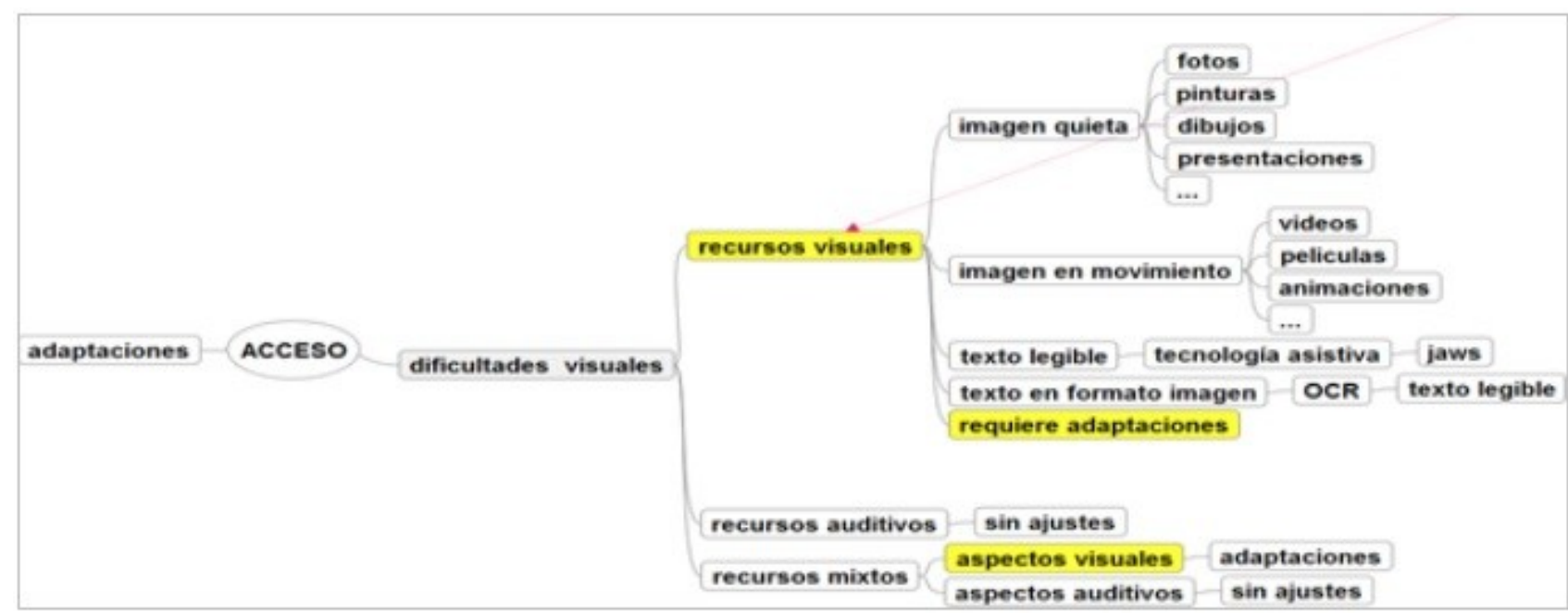

Fuente: Elaboración propia

Un recurso puede tener uno o más modos de acceso. Cuando el recurso no cumple los requerimientos de alguna preferencia o necesidad debido a que algunos de los modos de acceso no se corresponde con las preferencias del usuario, entonces se deberá generar un recurso adaptado. Este recurso adaptado reemplaza o aumenta uno o más modos de acceso. Una fotografía, por ejemplo, tiene modo de acceso visual. Si se genera una adaptación, por ejemplo una descripción de texto largo, la descripción tendrá modo de acceso textual y será un recurso equivalente a la fotografía.

De acuerdo a los distintos tipos de recursos se tendrán que generar adaptaciones específicas. Una situación bastante común es tener una presentación que involucra texto legible e imágenes sin texto alternativo; el modo de acceso es texto y visual, por lo cual la presentación será parcialmente accesible para alguien con dificultad visual. No obstante, si sobre la misma presentación se corrige y se adiciona texto alternativo para las imágenes, entonces el modo de acceso es texto, ya que los elementos visuales de la presentación disponen ahora de un texto alternativo.

La generación de recursos educativos accesibles ha sido objeto de preocupaciones por parte del Proyecto ESVIAL (2013). Este proyecto dispone de cursos abiertos sobre cómo generar materiales accesibles $\underline{1}$, algo que se ha replicado también en otros sitios $\underline{2}$.

En la Figura 3 se señalan algunas adaptaciones para el modo de acceso visual. El recurso adaptado tiene un modo de acceso que es diferente al modo de acceso del recurso original, ya que justamente es una adaptación. 
Figura 3.Adaptaciones visuales

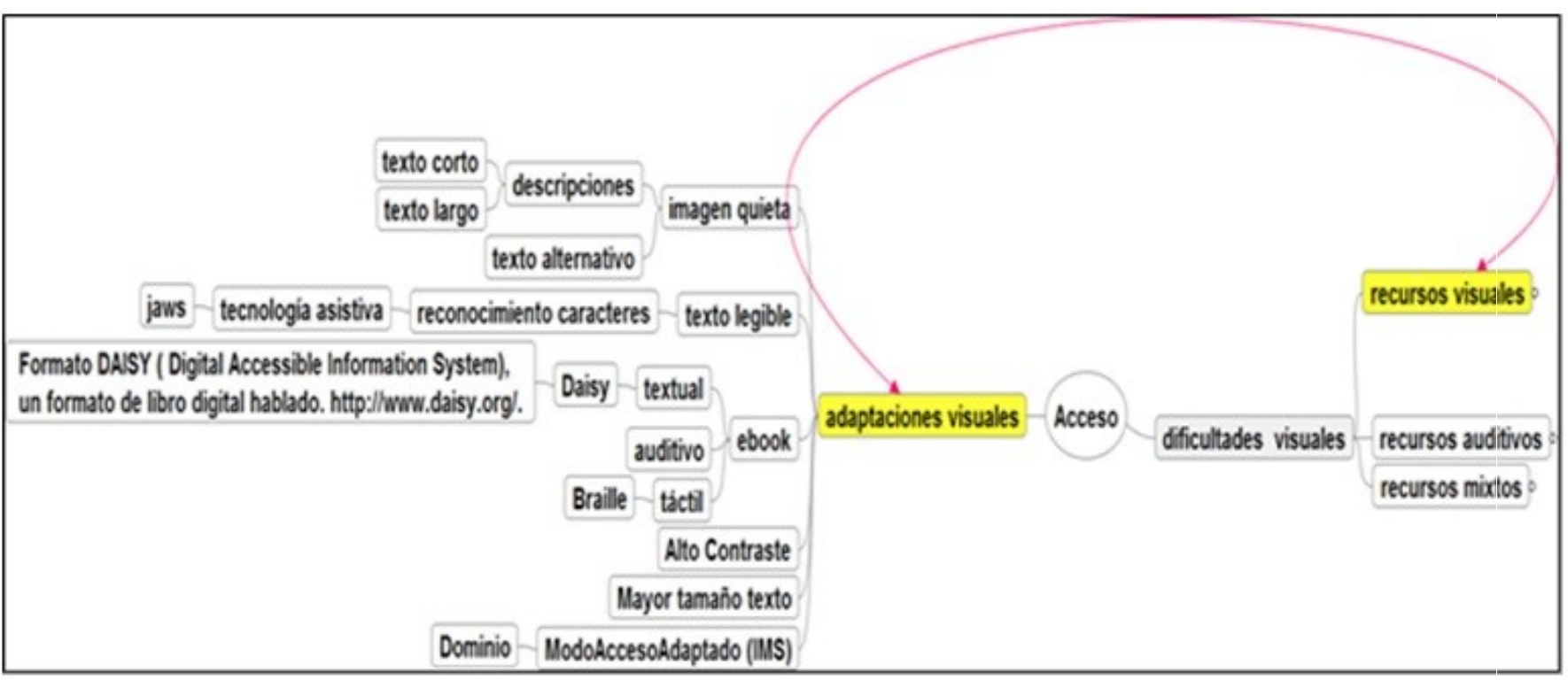

Fuente: Elaboración propia

Por ejemplo, un recurso 1 con modo de acceso visual requiere la confección de un recurso 2 con un modo de acceso textual.

Recurso 1: accessMode $=$ visual

Recurso 2: accessMode $=$ textual

accessModeAdapted $=$ visual

isAdaptationOf $=$ recurso 1

La especificación AfA PNP trata de las necesidades y preferencias del estudiante con respecto al mejor modo de interacción con los recursos digitales. Se concentra en los estudiantes con discapacidades pero también en cualquier estudiante en un contexto deshabilitante. Esta perspectiva enfoca el acceso como una cuestión funcional que no es una categorización permanente y aislada, sino contextual. La especificación puede ser usada para entregar la interface deseada o requerida al estudiante o en combinación con DRD, es decir, entregar los recursos digitales que se aparean con las necesidades y preferencias del estudiante.

Un contexto específico describe las condiciones bajo las cuales determinadas preferencias son establecidas. Un escenario ruidoso, por ejemplo, puede interferir con la entrega de recursos con audio, mientras que en otro escenario eso no es una preferencia.

Un estudiante puede tener diferentes contextos y, en cada uno de esos contextos, opera un conjunto de preferencias y necesidades diferentes. El perfil es necesario para establecer las necesidades, pero no para identificar al usuario, sino para identificar las necesidades del usuario con un criterio de funcionalidad.

La tecnología asistiva, como es el caso del lector de pantalla, permite el acceso a un texto para un usuario con dificultades visuales. Si el recurso visual es un texto legible (modo de 
acceso texto), el texto puede ser leído con un lector de pantalla como, por ejemplo, jaws (Freedom scientific, s.f.), por lo que no requerirá ajustes. En este caso en el perfil de preferencia del usuario figurará modo de acceso "textual"; lo mismo en el recurso, que puede ser entregado al usuario y cumplirá con la pauta de accesibilidad.

Si el recurso es un texto pero en formato imagen, el modo de acceso del recurso será "visual" y no se adecuará para ser entregado a un usuario que en su perfil de preferencia establezca "textual", porque el recurso no es legible con un lector de pantalla. Si este texto en formato imagen es sometido a un proceso de reconocimiento de caracteres, entonces su modo de acceso cambiará a "textual". En este caso hay un proceso de adaptación (OCR) y se genera un recurso equivalente. Un recurso original puede sufrir distintas adaptaciones y generar varios recursos equivalentes con un modo de acceso diferente. Para poder seguir el rastro de los recursos y sus equivalentes siempre se vincula el recurso equivalente con el original, no con otros equivalentes.

Como se muestra en el diagrama de la Figura 4, tanto el recurso original como el recurso equivalente tendrán un modo de acceso, pero el recurso equivalente tendrá un modo de acceso diferente al original. El dominio del modo de acceso en el recurso original y en el recurso equivalente es el mismo, y es el mismo dominio donde mapean las preferencias del usuario (texto, visual, auditivo).

Cuando los recursos visuales son imagen fija, o imagen en movimiento (modo de acceso visual), y precisan accederse desde un perfil que no tenga preferencia visual, requerirán adaptaciones. En el caso de imagen fija, por ejemplo, se requerirá un texto descriptivo de la imagen, ya sea corto o largo.

En ocasiones no es sencillo definir las adaptaciones ya que constantemente cambian los formatos o las modalidades y, de acuerdo con ello, irán variando las adaptaciones.

El libro electrónico, por ejemplo, puede estar en un formato textual y es adecuado para una preferencia texto. No obstante, un texto largo es difícil de manejar incluso con un lector de pantalla, pudiendo mejorarse el acceso si se pasa a un formato Daisy (Daisy Consortium, s.f.). Este formato contiene marcas, por lo que es más sencillo acceder a los capítulos o secciones sin tener que pasar por todo el libro para encontrar la parte buscada. También se podría generar un audiolibro con modo de acceso auditivo o táctil con Braille. 


\section{Figura 4. Diagrama UML conceptos IMS}

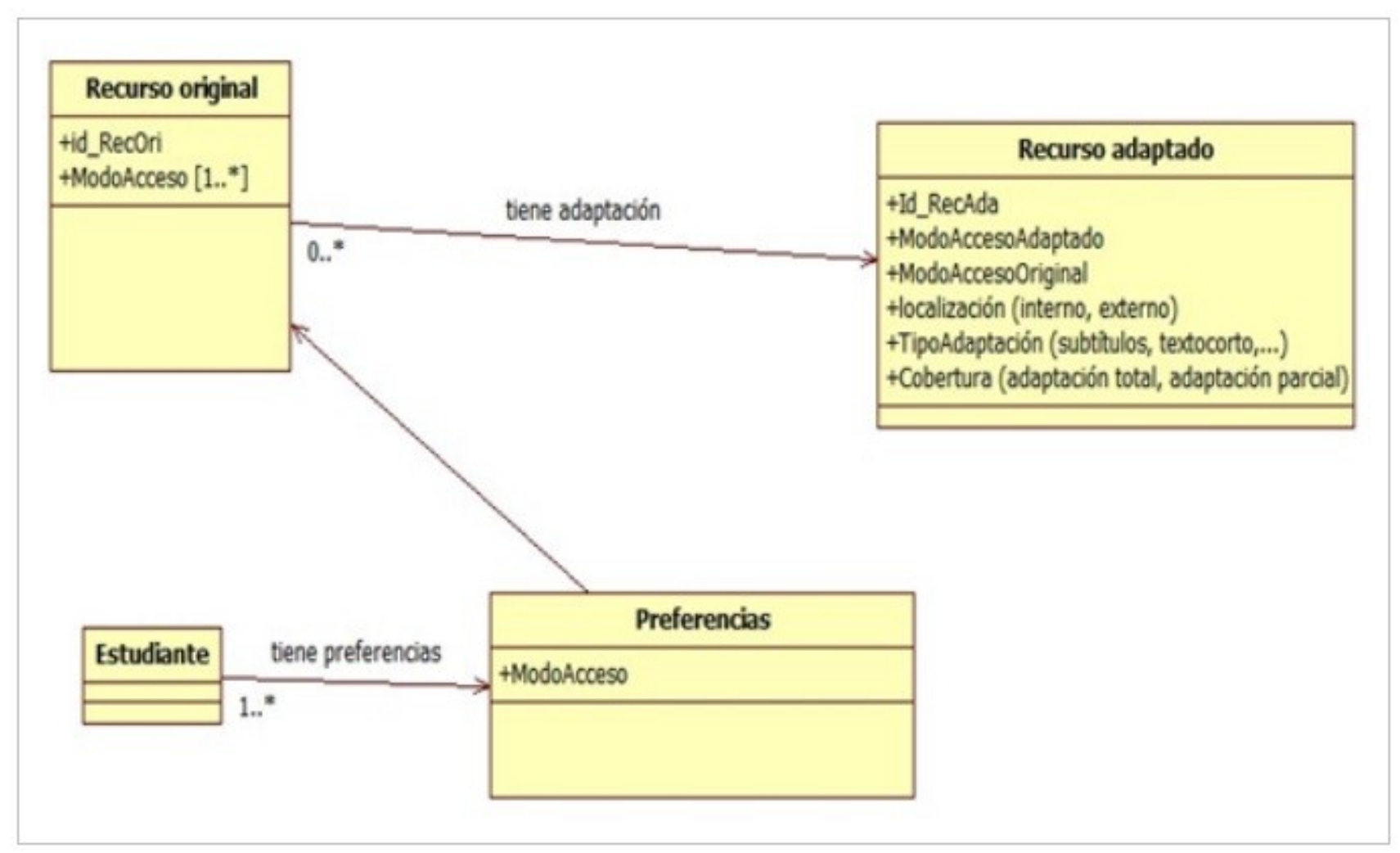

Fuente: Elaboración propia

Cuando se trata de dificultades auditivas y el recurso es una película, una adaptación podría ser el aporte de subtítulos. En este caso la adaptación no es completa sino parcial, la película no sufre cambios pero se le adicionan los subtítulos, mientras que en el caso de un diagrama visual que es descripto con un texto largo, la adaptación es completa.

La propuesta de accesibilidad de IMS está elaborada con el foco en la adaptación y la personalización de recursos, interfaces y contenidos que concurran a las necesidades individuales. La idea subyacente es que la mejor manera para que un sistema o recurso sea accesible a alguien en particular es cumplir con las necesidades particulares de esa persona en un contexto específico. La idea va más allá de la accesibilidad y se inscribe en la usabilidad para todos los contextos.

Esta propuesta (IMS Access for all v3.0 IMS Global Access for all, 2012) busca la inclusión del estudiante habilitando el apareo de las características de los recursos educativos a las necesidades y preferencias de los estudiantes. El ciclo comienza cuando aparecen necesidades en el mercado que son detectadas, analizadas y utilizadas por las instituciones de formación como guía para el diseño y desarrollo de la oferta formativa que demandan los clientes. La formación virtual desarrollada entonces es ofertada al mercado por estas instituciones. Cuando los recursos no son adecuados a las necesidades de los estudiantes, entonces se habilita un proceso de descubrimiento de recursos apropiados, los recursos equivalentes o alternativos. El énfasis está puesto en el desarrollo de un proceso de generación de recursos flexibles que se adapten a diferentes necesidades. No supone que un solo recurso sea totalmente accesible, sino que un conjunto de recursos 
cumplan los requerimientos de necesidades diferentes. La generación de metadatos para cada recurso facilitará la determinación de qué recursos precisarían adaptarse para las necesidades específicas de un estudiante.

El estándar tiene una parte que se ocupa de describir las necesidades y preferencias de los usuarios de los entornos virtuales. Esos datos registran la información de cómo el usuario puede interactuar con la computadora y de esta manera requerir un contenido adaptado a estas necesidades. Se habilita así el apareo de las características de los recursos a las necesidades y preferencias de los usuarios.

IMS Global Access For All Personal Needs and Preferences (PNP) v3.0 registra las necesidades y preferencias del estudiante respecto a la interacción con los recursos digitales, incluyendo la configuración de la tecnología asistiva.

IMS Global Access For All Digital Resource Description (DRD) v3.0 registra las características de los recursos de aprendizaje digitales, los cuales pueden ser adaptados para mejorar la accesibilidad.

Las especificaciones DRD y PNP v3.0 trabajan en conjunto para entregar a los estudiantes los recursos que se corresponden con sus necesidades y preferencias.

Los modelos conceptuales que subyacen a la especificación son independientes de una representación o implementación tecnológica en particular. El modelo prevé extensiones, la idea del modelo es un núcleo común que puede ser extendido de acuerdo a las necesidades particulares. Asegurando ese núcleo común que establece la interoperabilidad, pero siendo flexible a situaciones especiales que determinan la necesidad de extender el modelo, se garantiza el acoplamiento y la personalización.

Por último, puede mencionarse el estándar ISO/IEC 24751 (ISO/IEC $247511-1,-2,-3$, 2008; Batanero, García, García y Piedra, 2012), que está basado en el modelo IMS y establece un marco para describir y especificar las necesidades y preferencias de los estudiantes y los recursos educativos digitales.

De esta manera queda planteado en forma general el modelo que traza IMS. A continuación presentamos el estándar LOM.

\section{Learning Object Metadata (LOM)}

LOM-ES es un esquema de metadatos específico de aspectos educativos con un nivel de expresividad importante. Dublin Core también puede ser usado, pero es un esquema de metadatos genérico y no incluye aspectos educativos específicos, aunque tiene una gran sencillez y facilidad para completarse (Dublin Core Metadata Initiative, 2009).

Actualmente LOM -IEEE Learning Object Meta-Data- (GT9/GT8-SC36/AENOR LOM, 2008; Barker, 2011) es el estándar aprobado que goza de mayor aceptación (estándar IEEE 1484.12.1 - 2002), y ha sido adoptado también en la especificación de IMS Learning Resource Metadata.

El esquema de metadatos LOM es muy extenso. Los atributos se dividen en distintas categorías: general, ciclo de vida, meta-metadatos, educativas, técnicas, derechos, 
relaciones, anotaciones y clasificación, según se detalla en la Figura 5 . El esquema es extensible y también proporciona la oportunidad de abrir especificaciones concretas a través de taxonomías, como es el caso de la accesibilidad.

En lo que sigue se van a detallar algunos aspectos de estos metadatos que son de interés para los aspectos de accesibilidad.

\section{a) Categoría Técnica $\underline{4}$}

En la categoría técnica se describen los requisitos y características técnicas de este objeto educativo.

El atributo 4.1 es formato, y consigna el o los tipos de datos de todos los componentes del recurso digital. Este elemento de datos también debe ser utilizado para identificar el software necesario para acceder al objeto educativo.

Utiliza los tipos MIME que se basan en el registro IANA; puede ser consultado en tipos mime del registro IANA (2).

Un ejemplo de etiqueta en $\mathrm{xml}$ :

- <format $>$ text/html</format $>$

Es de remarcar que este elemento no corresponde al modo de acceso sino al formato del archivo. Por ejemplo, un pdf puede tener modo de acceso visual o textual.

Figura 5. Mapa mental LOM

\begin{tabular}{|c|c|c|c|c|c|c|c|c|}
\hline & & & & 1.1 lde & ontificador 1.1.1 Cat: & Eatalogo & & \\
\hline & & & & $1.2 \mathrm{Tt}$ & tulo 1.1 .2 Ent & Entrada & & \\
\hline & & & & $1.3 \mathrm{ld}$ & oma & & & \\
\hline & & & 1. General & 1.4 De & scripcion & & & \\
\hline & & & & $1.5 \mathrm{~Pa}$ & labra clave & & & \\
\hline & & & & $1.6 \mathrm{An}$ & nbito & & & \\
\hline & & & & $1.7 \mathrm{Es}$ & itructura & & & \\
\hline & & & & $1.8 \mathrm{Ni}$ & vet de agregacion & & & \\
\hline & 2. Ciclo de vida & & & & 3.1 Identificador & $3.1 .1 \mathrm{Ca}$ & talogo & \\
\hline & & & & & & $3.1 .2 \mathrm{E}$ & atrada & \\
\hline & & & 3. Meta-metac & datos & 3.2. Contribucion & $\begin{array}{l}3.2 .1 \mathrm{~T} \\
3.2 .2 \mathrm{Er}\end{array}$ & po & \\
\hline & & & & & & $3.2 .3 \mathrm{Fe}$ & cha & \\
\hline & & & & & 3.3 Esquema de met & hetadatos & & \\
\hline & & & & & 3.4 Idioma & & & \\
\hline 4.4.1.1 Tipo & & & & & 5.1 Tipo de inteactivic & vidad & & \\
\hline 4.4.1.2 Nombre & 4. Teenica & & & & 5.2 Tipo de recurso e & educative & & \\
\hline 4.4.1.3 Versión minima & 4. Teenica & LOM & & & 5.3 Nivel de interactiv & tividad & & \\
\hline 4.4.1,4 Versión maxima & & & & & 5.4 Densidad semánti & atica & & \\
\hline 4.5 & & & & & 5.5 Destinatario & & & \\
\hline 4.6 Otros requ & & & 5. Uso educat & tive & 5.6 Contexto & & & \\
\hline & & & & & 5.7 Rango tipico de e & edad & & \\
\hline & & & & & 5.8 Dificultad & & & \\
\hline $6.2 \mathrm{c}$ & & & & & 5.9 Tiempo tipico de & aprendiz & taje & \\
\hline & 6. Derecho & & & & 5.10 Descripeión & & & \\
\hline & & & & & 5.11 Idioma & & & \\
\hline & & & & & 5.12 Proceso cogniti & ivo & & \\
\hline & & & & 7.1 & Tipo & & & \\
\hline & 8. Anotación & & 7. Relación & & & & 7.2 .1 & Catalogo \\
\hline & & & 7. Relacion & 7.2 & 7.2 .1 Identi & tificador & 7.2 .2 & Entrada \\
\hline & & & & & & & 7.2 .3 & Descripción \\
\hline & & & & & 9.1 Propósito & & & \\
\hline & & & & & & $9.2 .1 \mathrm{~F}$ & wente. & \\
\hline & & & 9. Clasificaci & & 9.2 Ruta taxonómica & $9.2 .2 \mathrm{~T}$ & $a x \phi n$ & 9.2.2.1 identificador \\
\hline & & & & & 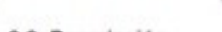 & & & 9.2.2.2 Entrada \\
\hline & & & & & $\begin{array}{l}9.3 \text { Descripción } \\
\text { 9.4 Palabras clave }\end{array}$ & & & \\
\hline
\end{tabular}


Fuente: Elaboración propia

\section{b) Categoría Relación (7)}

Esta categoría describe las relaciones existentes, si las hubiese, entre el objeto educativo y otros. Para definir relaciones múltiples deben utilizarse varias instancias de esta categoría. Si existen varios objetos educativos con los cuales éste está relacionado, cada uno de ellos tendrá una instancia propia de esta categoría.

7.1 Relación, se basa en las relaciones modeladas en Dublin Core:

- es parte de

- tiene parte

- es versión de

- tiene versión

- es formato de

- tiene formato

- referencia

- es referenciado por

- se basa en

- es parte de

- es base para

- requiere

- es requerido por

7.2. Recurso: El objeto educativo objetivo al que se refiere esta relación.

\section{c) Categoría Anotaciones (8)}

Esta categoría proporciona comentarios sobre la utilización pedagógica de este objeto educativo, e información sobre quién creó el comentario y cuándo fue creado. Esta categoría permite a los educadores compartir sus valoraciones sobre los objetos educativos, recomendaciones para su utilización, etc. Los materiales pueden tener asociadas múltiples anotaciones. Dichas anotaciones pueden caracterizarse por:

- El anotador que realiza la anotación.

- La fecha de la anotación.

- El texto en sí de la anotación

\section{d) Categoría Clasificación (9)}

Esta categoría describe dónde se sitúa este objeto digital dentro de un sistema de clasificación concreto. Para definir múltiples clasificaciones, deben utilizarse múltiples instancias de esta categoría.

9.1 .Propósito. El propósito que se persigue al clasificar este objeto educativo. El espacio de valores de esta clasificación puede ser la disciplina, idea, prerrequisito, objetivo 
educativo, restricciones de accesibilidad, nivel educativo, nivel de habilidad, nivel de seguridad, competencia.

9.2 . Ruta Taxonómica: El camino taxonómico dentro de un sistema de clasificación específico. Cada nivel sucesivo representa un refinamiento sobre la definición dada en el nivel precedente. Pueden haber diferentes caminos, en la misma o diferente clasificación, para describir la misma característica.

Dentro del perfil LOM ES v1 (Perfil de aplicación LOM-ES V1.0, 2009), es a través de la categoría 9 -clasificación- donde se puede introducir el concepto de accesibilidad; en particular, refiere a una taxonomía sobre accesibilidad que está en el anexo VII del perfil LOM-ES v1. El criterio de uso es taxonómico, el nivel superior es el más abarcativo y se desglosa en niveles de mayor granularidad. Existe en LOM el elemento que IMS consigna como "modo de acceso" y que en la taxonomía figura en dos elementos:

- En el identificador 1 como "modo de presentación de la información en el acceso", que se desglosa en los siguientes valores:

- Auditivo (con voz o sonido)

- Táctil

- Textual (visual por texto)

- Visual (solo por ícono)

- En el identificador 2 como "modo de presentación de la información dentro del objeto", que se desglosa en los siguientes valores:

- Auditivo (con voz o sonido)

- Táctil

- Textual (visual por texto)

- Visual (solo por ícono)

La diferencia entre los identificadores corresponde al concepto de LOM de niveles de agregación de los objetos de aprendizaje. El identificador 1 aplica al nivel 1 de objeto de aprendizaje que corresponde al nivel más granular funcional o físico: una fotografía, un mapa mental, etc. El nivel 2 es una agrupación de objetos atómicos de nivel 1, como por ejemplo una lección.

Cada elemento de la taxonomía señalado a su vez se subdivide en conceptos más detallados, por ejemplo:

- Informativo

- Decorativo

- Motivacional

También están presentes en la taxonomía del anexo VII en la categoría 8 de LOM-ES v1 la 
declaración de adaptabilidad y los tipos de adaptación. Las adaptaciones también tienen correspondencias con el modelo IMS. Se presenta un esquema en la Figura 6.

\section{Figura 6. LOM-ES Anexo VII de accesibilidad}

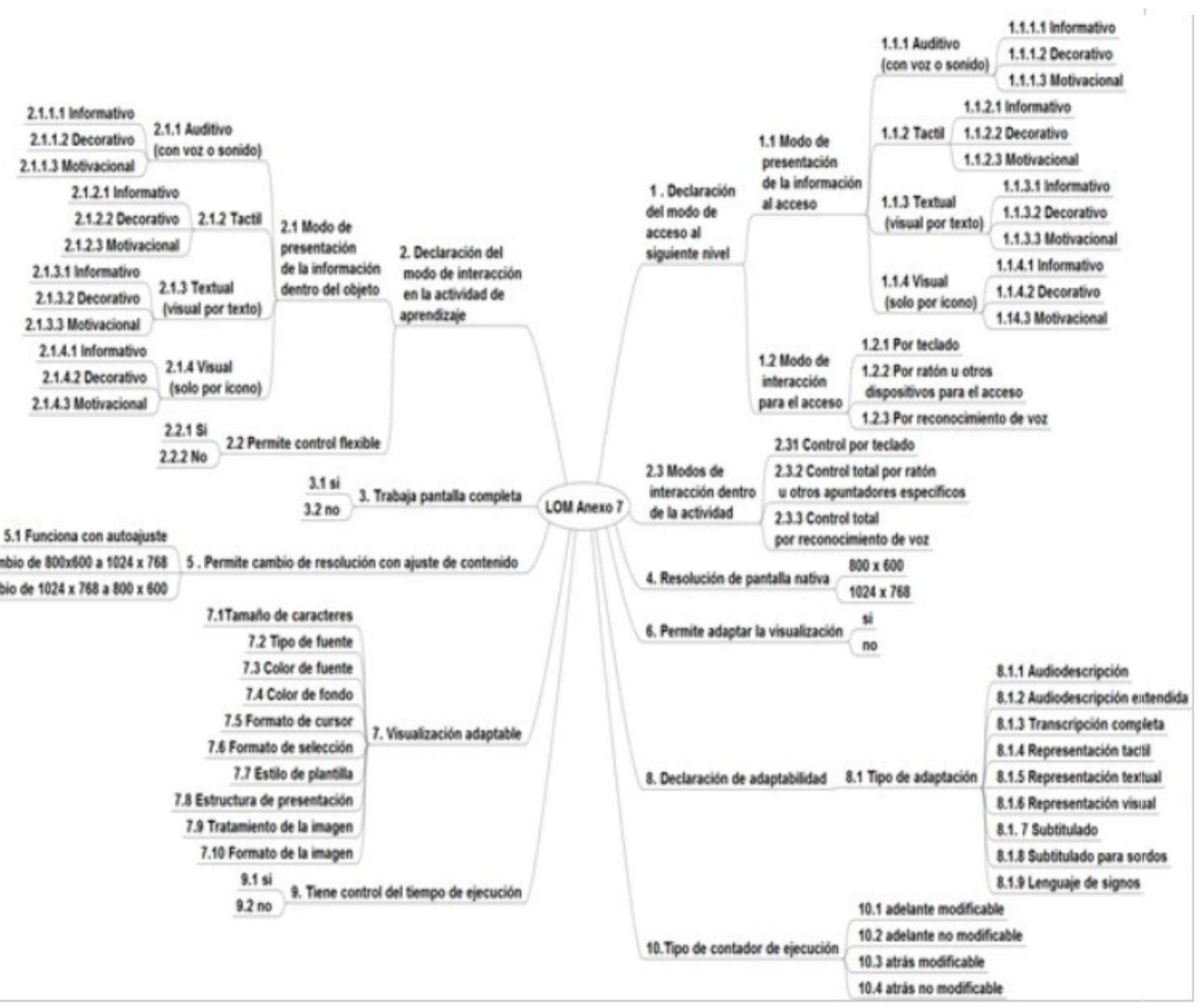

Fuente: Elaboración propia

\section{OBAA}

El estándar OBAA (Objetos de Aprendizaje Basados en Agentes; OBAA, s.f.), desarrollado para su aplicación en Brasil, es compatible con IEEE-LOM y su desarrollo apunta a permitir interoperar con otros sistemas y aplicaciones. Es un proyecto coordinado por la Universidad Federal de Rio Grande del Sur (UFRGS) $\underline{3}$, que tiene como objetivo también crear las bases tecnológicas que permitan efectivizar la adopción de la propuesta de metadatos de objetos de aprendizaje OBAA. Este proyecto es patrocinado, entre otras instituciones de Brasil, por el Ministerio de Educación, la Financiadora de estudios y proyectos (FINEP) del Ministerio de Ciencia y Tecnología y el Centro Interdisciplinar de tecnologías educativas (CINTED).

Los repositorios que han adoptado la propuesta se han nucleado en FEB (Federación Educa Brasil), cuyo objetivo es federar repositorios de objetos de aprendizaje, constituyendo en 
sí mismo una confederación.

Entre otros repositorios participan:

- LUME - Repositório Digital da Universidade Federal do Rio Grande do Sul

- CESTA - Coletânea de Entidades de Suporte ao uso de Tecnologia na Aprendizagem

- OBAA - Repositório de Objetos de Aprendizagem Baseados em Agentes

- BIOE - Banco Internacional de Objetos Educacionais

- BNDIGITAL - Biblioteca Nacional Digital Brasil

OBAA partió de analizar los principales sistemas de metadatos para objetos de aprendizaje (IEEE, IMS, DC.) y consideró las siguientes premisas (Milos, s.f.):

- Adaptabilidad e interoperabilidad: una misma descripción de un OA puede ser usada de forma interoperable, adaptándose a las características de las plataformas digitales como Web, TV Digital y dispositivos móviles.

- Compatibilidad con otros sistemas de metadatos.

- Accesibilidad: deben considerarse los aspectos inclusivos para dar acceso a todos.

- Independencia y flexibilidad tecnológica: capaz de soportar innovaciones tecnológicas, permitiendo extensiones sin perder compatibilidad con el contenido ya desarrollado.

La propuesta de metadatos para objetos de aprendizaje OBAA nace desde la confluencia entre las tecnologías de los objetos de aprendizaje y los sistemas multiagentes aplicados a este campo.

Los sistemas multiagentes o MAS (multi agent systems) según Poslad (2007):

son sistemas distribuidos, compuestos por un número de entidades de software autónomas Ilamadas agentes. En teoría los MAS son generalmente caracterizados en términos de comportamientos internos e interacción externa entre los agentes. Las principales propiedades para caracterizar el comportamiento interno de los agentes son: el tipo de cognición y la medida de desempeño que utilizan en elegir cómo actuar, por ejemplo, en forma reactiva, basados en modelos, basados en objetivos, basados en utilidades; cuan adaptativos son, como ellos caracterizan el entorno en el cual están situados, incluyendo la infraestructura computacional y su entorno social con otros agentes; y el grado de autonomía de sus acciones en su contexto con respecto a otros agentes, un propietario humano y su ejecución. Las principales propiedades para caracterizar el comportamiento externo observable de la interacción inter-agente son: cómo interactúan para compartir tareas e información; cómo interactúan como parte de diferentes tipos de organización social y el grado de cooperación con otros agentes (pp. 1-2).

Los objetos de aprendizaje (OA) son, desde esta perspectiva, un producto basado en los sistemas de agentes. Así, el OA busca ser interoperable en distintos entornos, como ser: web, tv digital, telefonía móvil, etc. 
El grupo de investigación propone una infraestructura de agentes que dé soporte a las funcionalidades previstas en la propuesta de metadatos OBAA. La infraestructura MILOS (Multiagent Infraestructure for Learning Object support; Milos, s.f.ab) está pensada para dar soporte a distintos procesos relacionados, entre otros:

- Autoría: asistencia para la creación de OA multimedia y multiplataforma.

- Catalogación y búsqueda de OA: dos aspectos complementarios. La asignación de metadatos en los OA para luego poder recuperarlos a través de la búsqueda en diferentes sitios (búsqueda federada).

- Repositorios: gestión en repositorios de OA con metadatos OBAA.

OBAA no solamente es una propuesta de estándar de metadatos para objetos de aprendizaje, sino que se ha implementado como una ontología. Asimismo, utiliza y conecta ontologías de dominio de enseñanza y aplicaciones educativas.

\section{a) Categoría 10: Accesibilidad.}

Los metadatos OBAA son una extensión del IEEE-LOM 1484.12.1.

Esta categoría no existía en LOM al momento de la generación de OBAA y tiene un criterio diferente a la actual extensión de LOM-ES (Perfil de aplicación LOM-ES v. 1.0 Anexo VII, s.f.).

10.1 Descripción del recurso. Se corresponde con el criterio IMS-DRD de IMS y se subdivide en el recurso primario y el equivalente. Se muestra el diagrama UML en la Figura 7.

\section{Figura 7. Diagrama UML Resource Description}

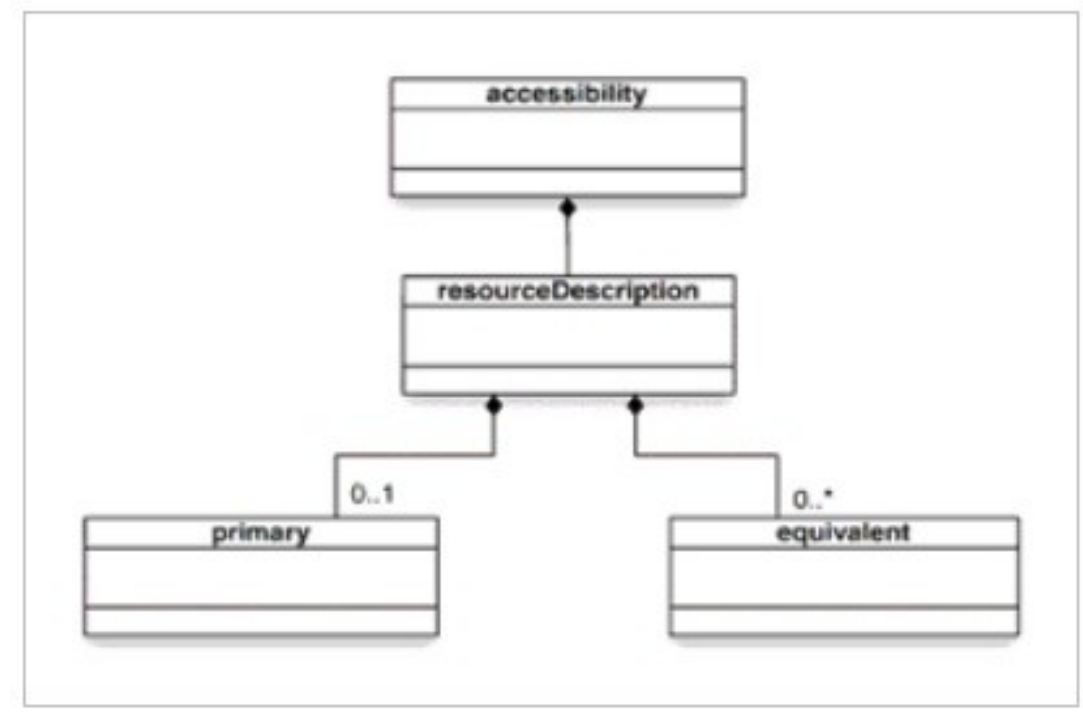

Fuente: Extraído de

http://www.imsglobal.org/accessibility/accmdv1p0/imsaccmd infov1p0.html\#1650841 
HasVisual: el modo de acceso es visual, el recurso es una imagen, un gráfico, etc. El dominio de valores es un booleano.

HasAuditory: el modo de acceso es auditivo, el recurso es una grabación, sonido, etc. El dominio de valores es un booleano.

HasText: el modo de acceso es un texto legible, pudiendo leerse con tecnología asistiva. Una imagen de un texto no tiene modo de acceso texto, sino visual. El dominio de valores es un booleano.

HasTactile: el modo de acceso es a través de elementos táctiles. El dominio de valores es un booleano.

Si el recurso es un documento con imágenes, entonces HasVisual y HasText tendrán el valor true.

10.1.1 Recurso primario

- 10.1.1.1 HasVisual

- 10.1.1.2 HasAuditory

- 10.1.1.3 HasText

- 10.1.1.4 HasTactile

- 10.1.1.5 EarlStatement. Se refiere al Evaluation and Report Language (EARL) que expresa una aserción en RDF.

<earl:Assertion rdf:about="http://example.org/\#assertion-1">

<earl:subject rdf:resource="http://example.org/\#OAeID02495"/>

$<$ earl:result rdf: resource="pass"/>

$<$ earl:mode rdf:resource="\&earl;manual"/>

<earl:testcase rdf:resource="http://example.org/\#tc-1"/>

<earl:assertedBy rdf:resource="http://example.org/\#assertor123" />

$</$ earl:Assertion>

En lo que antecede se expresa una aserción sobre un recurso http://example.org/\#OAeID02495, que se evaluó con un determinado test por un evaluador http://example.org/\#assertor123, y pasó el test.

En el caso de OBAA se evalúan objetos de aprendizaje respecto a los criterios de accesibilidad y específicamente se subdivide en dos aspectos: la transformabilidad Visual (DisplayTransformability) y la flexibilidad en el control (FlexibilityControl).

La presentación o visualización de algunos recursos puede ser transformada si al crearse se usa por ejemplo lenguaje de marcado. Existen herramientas que permiten determinar si la presentación de un recurso es susceptible de transformarse, como por ejemplo el tamaño de letra o el color de la fuente. 
Figura 8. Diagrama UML clase primary

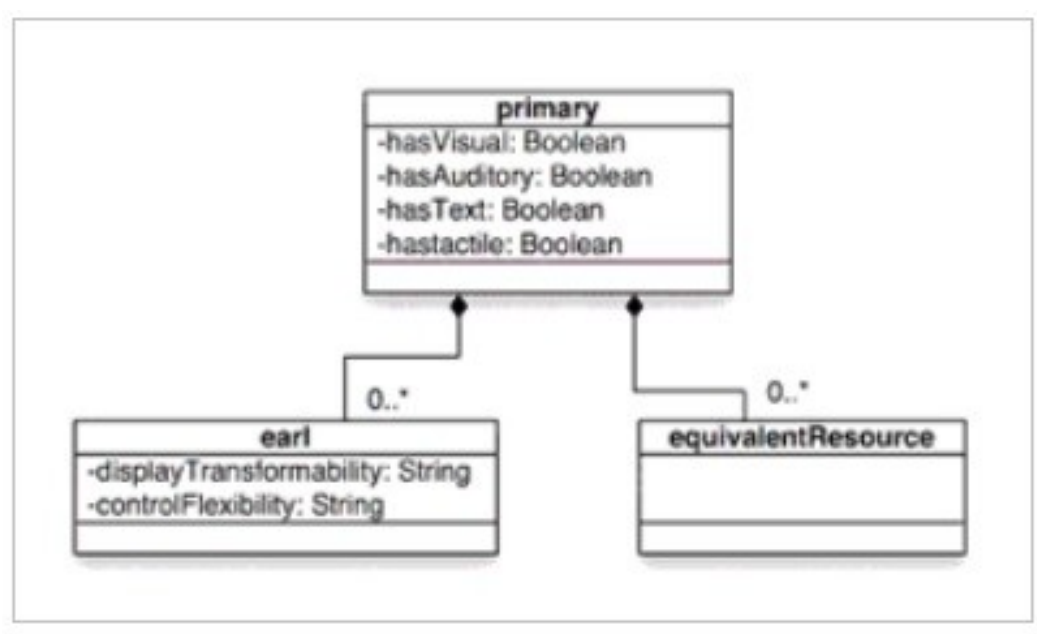

Fuente: Extraído de

http://www.imsglobal.org/accessibility/accmdv1p0/imsaccmd infov1p0.html\#1650841

Algunos recursos, por ejemplo, solo pueden ser controlados con un mouse; esto hace imposible ejercer el control del recurso a aquellas personas que tienen dificultades motrices. Si el control es flexible, permitirá también la manipulación a través de un teclado. La flexibilidad del control de un recurso especifica que existan métodos diversos para controlar el recurso.

Puede haber varias sentencias EARL, como se muestra en la Figura 8.

Un recurso que tenga 10.1.1.1 HasVisual no estará accesible para alguien con deficiencia visual, por lo que deberá generarse un recurso equivalente (10.1.1.6) al recurso primario que tenga algún tipo de adaptación.

10.1.1 Objeto de aprendizaje 1

- 10.1.1.1 HasVisual (true)

- 10.1.1.6 Objeto de aprendizaje 2

Luego se describe al objeto equivalente:

10.1.2 Recurso equivalente (Objeto de aprendizaje 2)

- 10.1.2.1 Recurso primario (Objeto de aprendizaje 1)

- 10.1.2.2 Archivo recurso primario

- 10.1.2.3 Suplementario. Este atributo indica si el recurso equivalente es una alternativa completa o parcial del recurso primario. Si el recurso equivalente es total, el valor es true, y false si es parcial.

- 10.1.2.4 Contenido (contenedor)

- 10.1.2.4.1 AlternativesToVisual. Esta opción se subdivide en las diferentes alternativas a lo visual: Audiodescripción, descripción corta, descripción larga, 
evitar color, etc.

- 10.1.2.4.2 AlternativesToText. Esta opción se subdivide en las diferentes alternativas a lo textual: alternativa gráfica, lenguaje de signos.

- 10.1.2.4.3 AlternativesToAuditory: Esta opción se subdivide en las diferentes alternativas a lo auditivo. Subtítulos, lenguaje de signos, etc.

- 10.1.2.4.4 LearnerScaffold.

El concepto Scaffold refiere al apoyo; tutoría durante el proceso de aprendizaje que se personaliza de acuerdo a las necesidades del estudiante. El soporte puede incluir la tutoría, la adaptación de la tarea o indicaciones, así como la inclusión de recursos suplementarios.

En el caso del atributo indica facilidades de acceso al aprendizaje, describiendo recursos que están o serán incluidos en el OA como herramientas de apoyo: diccionario, tesauro, herramienta de mapas mentales, etc.

En la Figura 9 se señalan algunos mapeos entre OBAA y el anexo VII perfil LOM-ES V1.0 a modo de ejemplo, aunque el contexto no se tomó en cuenta porque la concepción de estructuración es diferente.

\section{Figura 9. Mapeo parcial de elementos OBAA- LOM-ES V1.0}

\begin{tabular}{|l|l|}
\hline OBAA & LOM-ES V1.0 \\
\hline HasVisual & visual \\
\hline HasAuditory & auditivo \\
\hline HasText & textual \\
\hline HasTactile & táctil \\
\hline AudioDescription & Audiodescripción \\
\hline AltTextLang & Transcripción completa \\
\hline
\end{tabular}

Fuente: Elaboración propia

\section{Propuesta de metadatos de accesibilidad}

Analizada la adecuación de los metadatos LOM con respecto al modelo IMS, se consigna que el modo de acceso de IMS tiene una analogía de la taxonomía accesibilidad de LOM con su concepto de "modo de presentación de la información en el acceso", y que el concepto de recurso equivalente también está presente.

A partir de todos los elementos analizados se propone adherir al modelo conceptual de IMS que resulta relevante, pero realizar una simplificación operable del mismo.

El estudiante tiene un modo de acceso y el recurso tiene otro, si ocurre que estos modos de acceso no están acordes se puede desarrollar un proceso de adaptación.

El proceso de adaptación consiste en que el docente, frente a un recurso que no es accesible, confeccione un recurso equivalente al original pero con una adaptación que lo hace accesible, poniéndolo a disposición y estableciendo el vínculo entre el recurso original 
no accesible y la adaptación accesible para que el estudiante pueda encontrar los recursos que sean adecuados a sus necesidades y preferencias.

Los elementos incorporados son el modo de acceso en el estudiante y el modo de acceso en el recurso. Esto permite realizar una confrontación estudiante-recurso, como se expresa en la Figura 10.

\section{Figura 10. UML Estudiante y recurso}

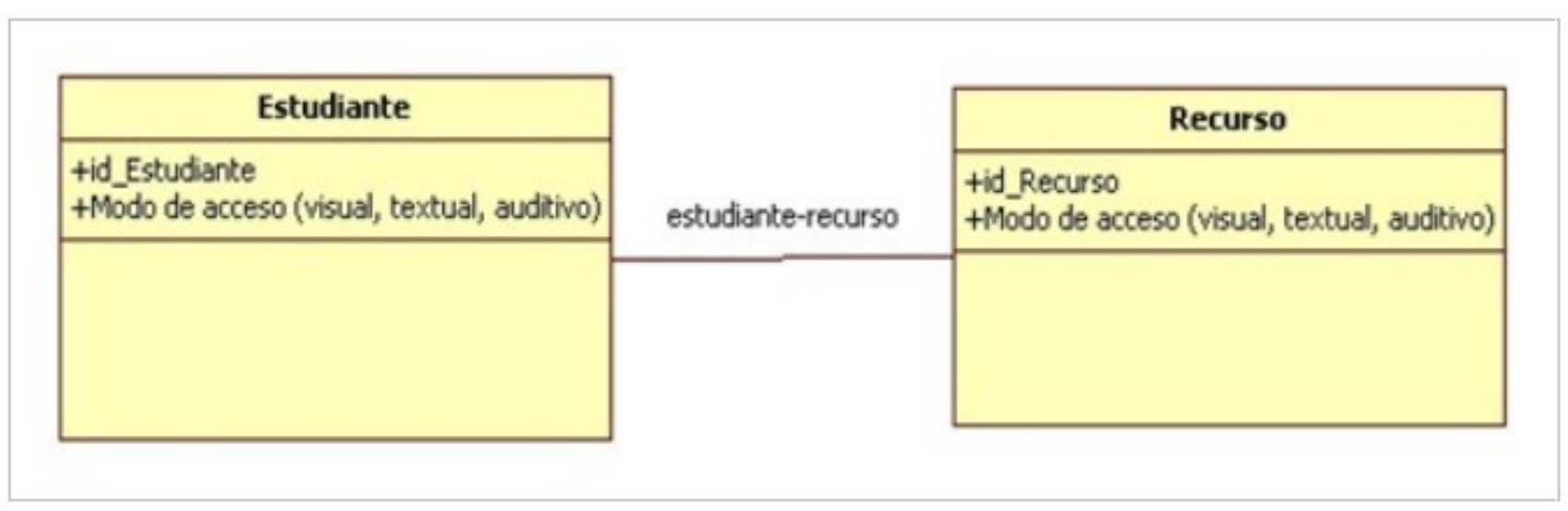

Fuente: Elaboración propia

El otro aspecto que corresponde a IMS y que resulta relevante es la explicitación de recursos equivalentes a un recurso original, como se expresa en la Figura 11.

\section{Figura 11. UML Recursos equivalentes}

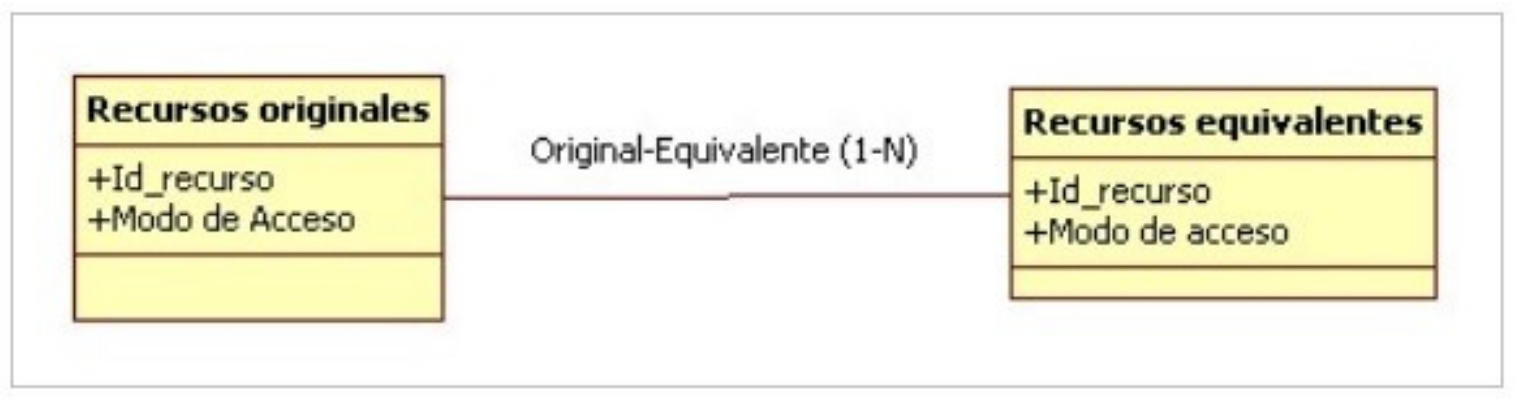

Fuente: Elaboración propia

Con la incorporación de estos dos elementos se pueden implementar las siguientes operaciones:

- Los estudiantes pueden consignar su perfil en cuanto al modo de acceso para que se establezcan claramente sus necesidades.

- Los docentes ingresan el modo de acceso de los recursos (originales y equivalentes) y cuando generan un recurso equivalente informan a qué recurso original corresponde. 
- Un estudiante que tiene un perfil con un modo de acceso que no corresponde con el que tiene un recurso ofrecido en un curso, puede buscar un recurso equivalente que se adecúe a su perfil.

Se plantea además la anotación de un recurso en cuanto a su modo de acceso, así como cualquier comentario que resulte pertinente. Resulta de interés consignar a quien realiza la anotación (rol): estudiante, profesor o aplicación.

La anotación de un recurso adhiere a la idea de LOM de establecer comentarios sobre los recursos, pero además se le adicionan dos elementos: el modo de acceso que tiene el recurso y el rol del que realiza la anotación (estudiante o profesor). En la figura 12 se explicita el diagrama UML.

\section{Figura 12. UML Anotación}

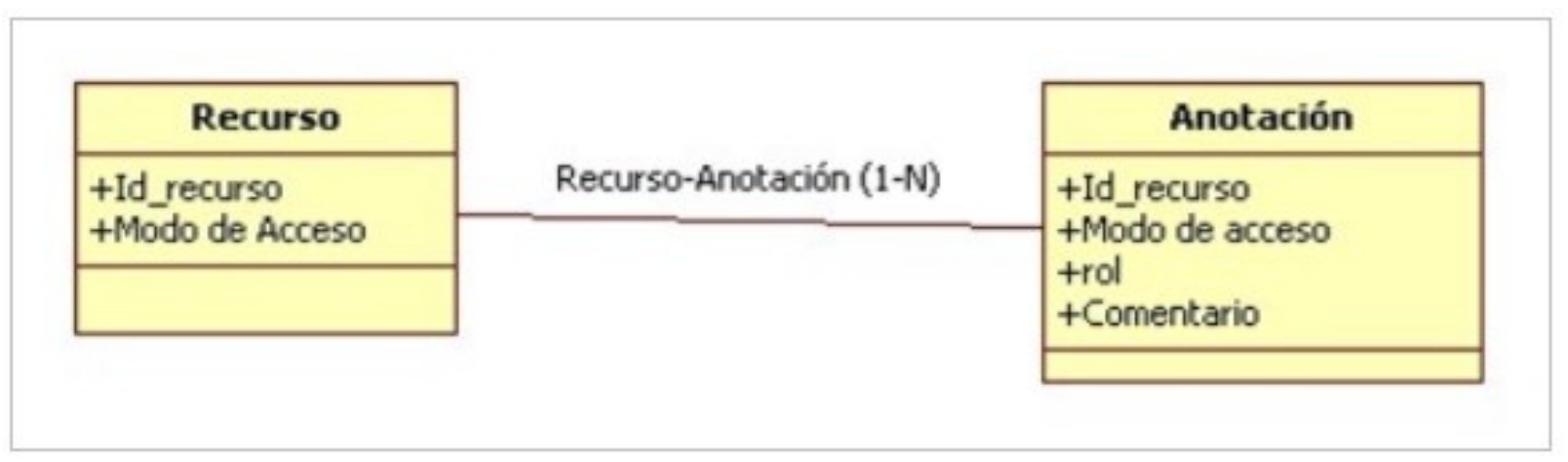

Fuente: Elaboración propia

En el siguiente diagrama de la Figura 13 se consignan los cambios propuestos a LOM y a OBAA. En azul se muestran las incorporaciones a LOM y en rojo las coincidencias con OBAA según se detalla:

- En la categoría 7, se incorpora a LOM el tipo de relación: "Es equivalente a" o "Tiene equivalente" (en el sentido de accesibilidad).

- En la categoría 8, se incorpora a LOM la Anotación de los aspectos de accesibilidad (modo de acceso) y quién realiza la anotación en cuanto al rol (estudiante, profesor, aplicación).

- La categoría 10 (Accesibilidad), que abre OBAA en forma específica y no dentro del anexo 7 de las taxonomías, nos parece que es apropiada, pero con un sentido de despojamiento que consigne los aspectos sustantivos, proponemos el uso del metadato modo de acceso con valores que mapeen en un dominio que tenga los elementos visual, textual y auditivo. 


\section{Figura 13. Mapa mental de LOM con incorporaciones}

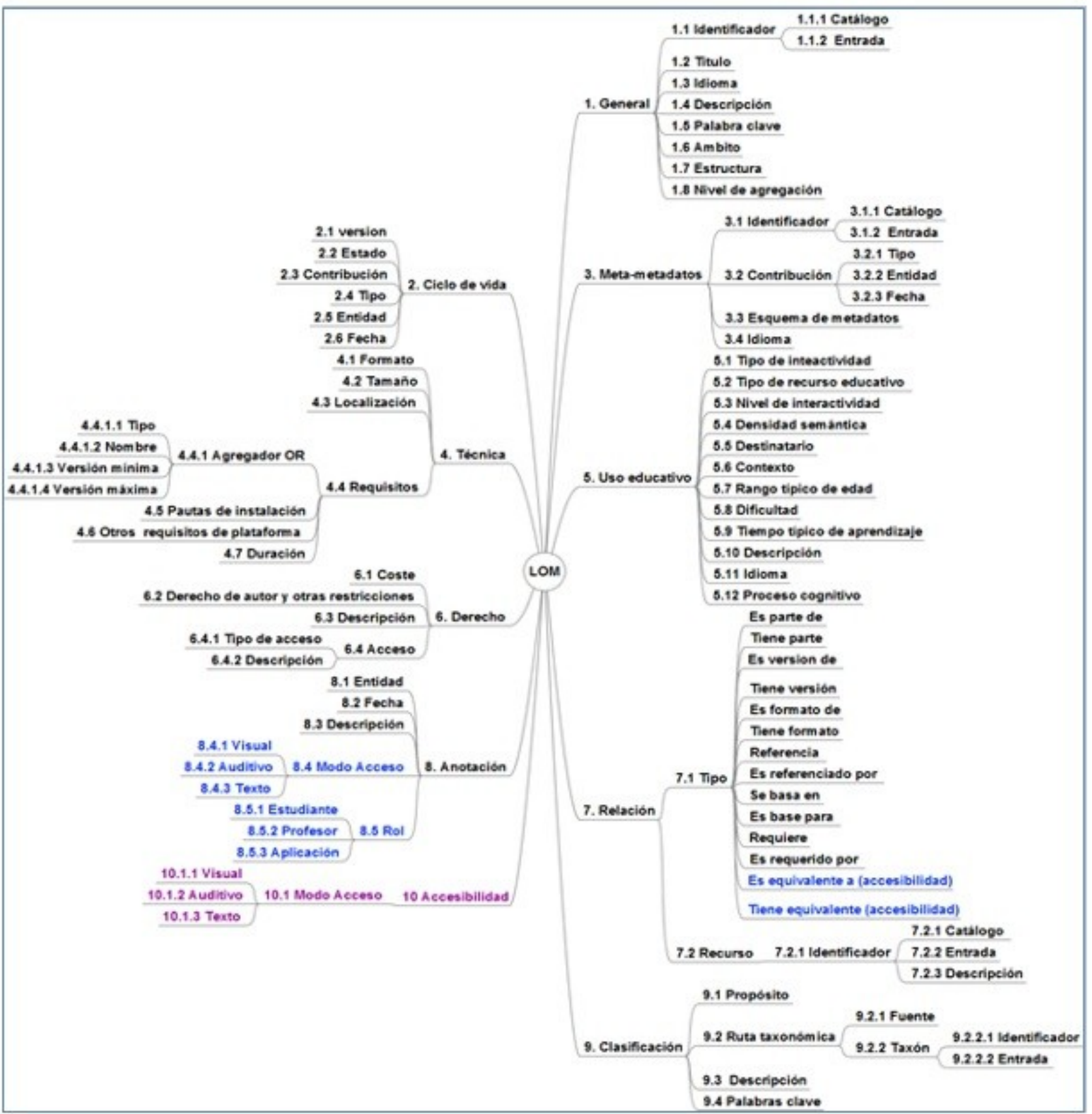

Fuente: Elaboración propia

La relación Original-Equivalente se puede modelar con el metadato LOM de la categoría Relación. El atributo 7.1 que consigna el tipo de relación no prevé la relación de equivalencia en cuanto a accesibilidad, por tanto se propone incluir un elemento nuevo que modele la relación "es equivalente a" en el sentido de la accesibilidad de IMS. Esto sería una extensión en el dominio de valores.

LOM establece que para modelar relaciones múltiples se deben consignar varias 
instancias. Esto es especialmente aplicable al caso de la relación de Es equivalente a, o Tiene Equivalente, porque un recurso primario puede tener varios recursos equivalentes con distintas adaptaciones.

La categoría Anotación de LOM prevé anotaciones y en este caso se extiende a un par de atributos (modo de acceso y rol) para consignar específicamente anotaciones sobre los aspectos de accesibilidad. La anotación podría dejar de ser genérica y convertirse en una anotación específica de accesibilidad. Interesa consignar además del objeto, la fecha y la observación, en particular el modo de acceso que puede aportarse o corregirse, y el rol de quien realiza la anotación (estudiante, profesor, software). El elemento entidad modela el origen de la anotación con generalidad (persona u organización) dando un identificador, pero interesa modelar cuál es el rol del que anota: estudiante, profesor o aplicación. De esta especificación del rol pueden dispararse acciones y contextualizarse distintos puntos de vista.

Desde el entorno virtual se puede realizar la exportación de los recursos y sus metadatos (incluyendo los metadatos de accesibilidad propuestos) con la idea de que los recursos puedan compartirse en repositorios de recursos abiertos accesibles. El hecho de ser cuasi compatible con LOM, salvo por las extensiones señaladas, hace que esta tarea resulte más sencilla. Se diseñó un modelo XML para la exportación de metadatos de accesibilidad en el prototipo propuesto.

Aportar el modo de acceso de los recursos por parte del autor o del profesor que incorpore el recurso en la plataforma educativa es una operación sencilla que no requiere más que una comprensión del concepto. En esta tarea, el profesional de la información dentro del entorno virtual también puede cumplir un papel de importancia.

Si el estudiante busca entre los recursos adaptados encontrará (si existe) la adaptación que requiere para su modo de acceso o, si no está generada, podrá pedirle al profesor que la produzca; incluso puede dejar consignada esta necesidad a través de los comentarios, lo cual genera una dinámica que va modelando un proceso de adecuación de los materiales de acuerdo a las necesidades de los estudiantes.

El modo de acceso del recurso adaptado será en algo diferente al recurso original; el recurso adaptado tiene un modo de acceso y éste deberá ser consignado para que pueda saberse cuál es la adaptación que se requiere en cada caso en particular.

De esta manera, desde el punto de vista operativo, la manipulación de los recursos en un entorno virtual es manejable por actores interesados en ser inclusivos, y la información está accesible para todos los involucrados, profesores y alumnos, permitiendo así una interacción dinámica que favorece la generación de cursos accesibles.

Con esta simplificación los profesores no deberán ser expertos en aspectos de accesibilidad, podrán ir generando conocimiento sobre estos temas y mejorar la accesibilidad de sus cursos. Los alumnos tendrán también una herramienta que les permita explorar si existen recursos adaptados para aquellos que no correspondan con su modo de acceso, y podrán pedir soluciones a sus profesores.

Lo ideal es que los cursos proporcionen recursos accesibles desde el inicio con todas las adaptaciones posibles. Sin embargo, esta opción no es siempre practicable. Los cursos 
sufren las contingencias de la organización académica, las dificultades técnicas de los productores de materiales, la falta de conocimiento para confeccionar los materiales accesibles, la falta de una política institucional o pautas de buenas prácticas, de modo que los cursos nacen y crecen en forma desordenada en cuanto a la accesibilidad.

La idea es favorecer un proceso de mejoramiento continuo, que represente un esfuerzo de mejoramiento y un desafío de creatividad e innovación, no uniformizar los entornos virtuales sino favorecer la inclusión.

Veamos por ejemplo el recurso mapa mental, que es un recurso valioso desde el punto de vista pedagógico que genera interesantes procesos cognitivos. El mapa mental permite al alumno situarse en la taxonomía del conocimiento que se está impartiendo y, al cerrar y abrir sus ramas, puede pasar de una visión detallada a una visión a grandes rasgos, ocultando y mostrando una estructura de conocimiento arborescente sin perderse ni dejar de visualizar los elementos que componen ese conocimiento o sus relaciones. El mapa mental tiene un modo de acceso visual. Podría generarse una adaptación que hiciera una descripción textual del mapa mental, pero eso no suplementaría las ventajas cognitivas que éste proporciona, porque es una representación estática de los conceptos con todas las ramas desplegadas y el poder del mapa mental es su navegación abriendo y cerrando ramas, pasando del concepto granular al bosquejo general, permitiendo situarse en cada desglose sin perder de vista los aspectos globales, geolocalizando el conocimiento. Esto no debiera inhibir el uso de mapas mentales, ya que si es un recurso adecuado para algunos modos de acceso puede ser útil para la labor pedagógica. Lo que es necesario es generar una adaptación adecuada para un mapa mental; esta adaptación podría ser una tabla de contenido al estilo de los libros, que sea navegable en un documento de procesador de texto con capítulos, secciones, subsecciones, etc., que pueda navegarse a lo largo y a lo ancho, es decir, por los agrupamientos generales y por los desarrollos específicos, abriendo y cerrando, yendo de la sección a la tabla de contenido, a otro capítulo y a otra sección, yendo y viniendo para así reconocer la taxonomía del conocimiento impartido. Este sucedáneo cumpliría el mismo papel que el mapa mental y sería una adaptación creativa. El proceso de creación de una adaptación como ésta puede irse ajustando y mediando a través de la participación de los estudiantes o tutores, que van expresándose y dejando una traza de cómo es el funcionamiento de los recursos, permitiendo un proceso creativo que se va delineando a partir de la interacción de los distintos aportes y puntos de vista.

El proceso que se va dando es que el profesor coloca un recurso que considera adecuado desde el punto de vista pedagógico y le registra el modo de acceso que le corresponde. Luego, cuando un estudiante con un modo de acceso no compatible quiere utilizar el recurso, se genera la dinámica para que el tutor o profesor cumpla con la necesidad de generar un recurso equivalente adecuado, favoreciendo los procesos para generar alternativas adecuadas y creativas. Se estimula así un proceso de mejoramiento continuo en la calidad de los recursos y en su adaptación en los aspectos de accesibilidad que se desarrolla "a medida".

En este sentido, la visibilización de los modos de acceso del estudiante y de los recursos, la posibilidad de generar la relación entre un recurso original y uno equivalente, y que se 
pueda buscar y usar, es un hito en un camino flexible en busca de mejorar la accesibilidad y la calidad, partiendo de una realidad posible pero con un acicate de mejoramiento continuo.

La posibilidad de realizar comentarios sobre los recursos, y en particular sobre los aspectos de accesibilidad de los mismos, permite generar una auditoría de los problemas de accesibilidad que puedan presentar. Esta auditoría es fundamental para que el docente inicie un proceso de mejoramiento y adecuación. Por otra parte, si el recurso no tuviera definido su modo de acceso o si estuviera controvertida su definición, el comentario, además de explicitar una situación, puede aportar el modo de acceso, con lo cual se facilita el aporte de este metadato o su corrección.

La posibilidad de participación de los actores involucrados (tutores, estudiantes), corporizada en los comentarios, aparece como una explicitación de la importancia de una visión interactiva del proceso de enseñanza aprendizaje que se permea también a los recursos. Esta visión colaborativa o 2.0, signo de nuestro accionar en la web, alcanza a la educación $y$, en particular, a un aspecto como la accesibilidad que se beneficia y autoalimenta de la misma.

Lo que persigue la propuesta es justamente la facilitación de esos procesos de mejoramiento y adecuación. El logro de la accesibilidad es visto como un proceso con la participación activa de los involucrados, brindando al estudiante un marco de participación protagónico que dinamiza las acciones y sensibiliza a los actores.

\section{Implementación en Moodle}

Para prototipar la propuesta se eligió Moodle, por ser una de las aplicaciones más usadas para entornos virtuales y porque es la que se usa en la Universidad de la República, en Uruguay, donde se desarrolló la investigación.

Moodle como aplicación de entornos virtuales de aprendizaje es una de las más extendidas ya que, entre otros aspectos, ha mantenido su estabilidad a la vez que habilita cambios y nuevas prestaciones.

El prototipo constituye un complemento que se adiciona a Moodle, respetando el núcleo de la aplicación y haciendo uso de la modalidad establecida para el crecimiento en nuevas prestaciones a través de complementos.

Tiene una licencia de software libre y se puede descargar de:

https://sourceforge.net/projects/accinformacinrecursos/?source=directory https://sourceforge.net/projects/accinf/?source=directory

\section{Conclusiones}

La propuesta de metadatos de accesibilidad no se ciñe ni a LOM ni a OBAA en forma absoluta, sino que, como se especifica en la Figura 14, contempla ambas propuestas.

Los cambios a LOM se señalan en colores: 
- categoría 7 Relación. Incorporación de equivalente en el sentido de accesibilidad (7.1 tiene equivalente).

- categoría 8 Anotación. Incorporación de comentario concreto de accesibilidad (8.4 y 8.5).

- categoría 10 Accesibilidad. Detallando modos de acceso, que es una incorporación fragmentaria de la propuesta de OBAA.

Está resaltado en amarillo el metadato modo de acceso, que es el eje del planteo.

Figura 14. Metadatos de accesibilidad

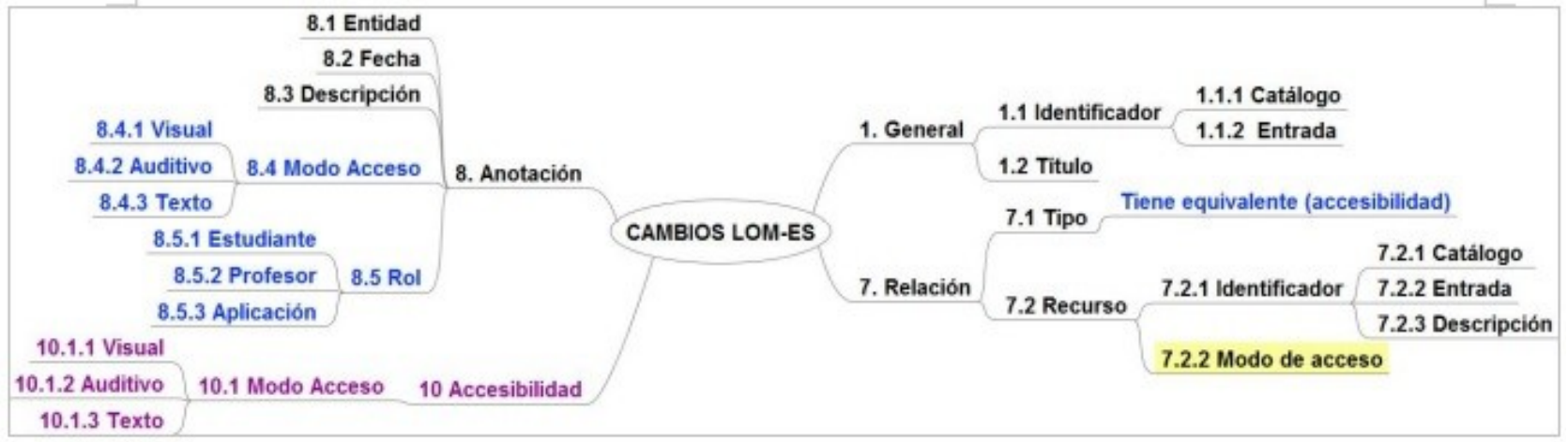

Fuente: Elaboración propia

El perfil LOM-ES V1.0 anexo VII es muy taxativo en cuanto a cuestiones tecnológicas que cambian constantemente y son complejas de establecer, como es el caso de "resolución de pantalla nativa: $1024 \times 768$ ". En este caso, la opción de proponer una sentencia EARL como lo hace OBAA parece más flexible, adaptable y sencilla, permitiendo establecer un criterio práctico. No obstante sería interesante ejemplificar sentencias EARL para los elementos más comunes, como los señalados en LOM-ES V1.0: tamaño de caracteres, tipo de fuente, color de fuente, etc.

Lo que merece una reflexión en el perfil OBAA es el señalamiento de la relación de equivalencia en un punto específico, cuando ya existía en LOM una categoría relaciones que podía albergarla.

Otro aspecto a señalar es que las adaptaciones son muy explicitadas tanto en OBAA como en LOM-ES V1.0, y habría que analizar el interés en consignarlas desde un punto de vista de uso.

Resulta de gran interés en OBAA el establecimiento de interoperabilidad -como es uno de sus objetivos- con los otros estándares de mayor uso. Es para remarcar el enfoque práctico y aplicado al ecosistema de los aspectos educativos desde la generación de editores y herramientas de autor, ontologías y repositorios, entre otros aspectos.

En suma, la realidad modelada es compleja porque comprende muchos elementos. Estos están interrelacionados y los conceptos que se manejan en los aspectos pedagógico y 
técnico son abundantes, a la vez que forman parte de dominios de conocimiento especializado. El compromiso de implementar información de calidad a través de los metadatos requiere de un conocimiento especializado que es difícil de instanciar operativamente.

Como modo de facilitar la operativa, la propuesta elige un conjunto de metadatos muy pequeño en relación a los que contienen los estándares y modelos analizados. No obstante, los metadatos propuestos contienen una información suficiente para la implementación del modelo IMS, permitiendo desarrollar el concepto de vínculo entre el perfil de preferencias del estudiante y las características de acceso de los recursos, a través del metadato modo de acceso (visual, auditivo, textual).

En la propuesta se ha preferido una adherencia a un conjunto de metadatos mínimo y se ha dejado abierta la posibilidad de escalar y profundizar más adelante.

Por otra parte, el hecho de que se haya abierto un espacio de interacción constituye una fuente de información rica, que podría aportar información sobre aspectos prácticos de uso de los recursos. Por ejemplo, si tenemos un comentario sobre dificultades para visualizar un recurso en determinada resolución de pantalla, ese comentario puede, por un lado, disparar un proceso para solucionar el problema concreto y, por otro, está también aportando en forma indirecta información técnica que no está siendo relevada por un metadato, sino a través de comentarios.

En este sentido, cabe señalar que el programa del Reino Unido para los objetos de aprendizaje (JISC CETIS, 2012) realizó una discusión sobre si definir un perfil de metadatos (UK LOM) obligatorio, o tomar en cuenta líneas como la anotación informal, como es el caso de las folksonomías o el uso de plataformas de colaboración como Youtube o Slideshare.

El eje de la propuesta aquí planteada es la concepción de la accesibilidad como una construcción colaborativa en la que, a partir de la participación, se va propiciando un proceso de reutilización y adaptación, en particular en los aspectos de accesibilidad.

Otro aspecto que se considera son los trayectos desde los entornos virtuales a los repositorios y viceversa, buscando tomar en cuenta la riqueza que pueda darse en cada enclave recopilando metadatos que son útiles para el proceso de mejoramiento de los recursos educativos.

Se abre un espacio de investigación respecto a cómo la interactividad opera como estrategia en el aporte de algunos metadatos o de su mejoramiento, y cómo este proceso favorece la accesibilidad.

\section{Notas}

1 http://www.esvial.org/cursos/materiales accesibles.html?trk=profile certification title

$\underline{2}$ Uruguay Udelar. Facultad de Información y Comunicación. Instituto de Información. 
3 http://www.iana.org/assignments/media-types/media-types.xhtml

4 http://www.ufrgs.br/ufrgs/inicial

\section{Referencias bibliográficas}

Barker, P. (2011). What Is... What is IEEE Learning Object Metadata / IMS Learning Resource Metadata? JISC CETIS standards briefings series. Recuperado de http://publications.cetis.ac.uk/wp-content/uploads/2011/02/WhatIsIEEELOM.pdf [Consulta: 25/11/2016].

Batanero, C., García, E., García, A., y Piedra, N. O. (2012). Norma ISO/IEC 24751: acceso para todos. En Actas del III Congreso Iberoamericano sobre Calidad y Accesibilidad de la Formación Virtual: CAFVIR, pp. 105-112 Recuperado de http://www.esvial.org/wpcontent/files/paper_Cafvir105.pdf [Consulta: 25/11/2016].

Daisy Consortium. (s.f.). Creating the best way to read and publish. Recuperado de http://www.daisy.org/ [Consulta: 25/11/2016].

Dublin Core Metadata Initiative (2009). Guidelines for Dublin Core Application Profiles. Recuperado de http://dublincore.org/documents/profile-guidelines/ [Consulta: 25/11/2016].

Felder, R.M., y Silverman, L. K. (1988). Learning and teaching styles in engineering education. Engr. Education, 78(7), 674-681. Recuperado de: http://www4.ncsu.edu/unity/lockers/users/f/felder/public/Papers/LS-1988.pdf [Consulta: 25/11/2016].

Freedom scientific. Blindness solution: jaws: The world's most popular windows screen reader. Recuperado de http://www.freedomscientific.com/JAWSHQ/JAWSHeadquarters01 [Consulta: 25/11/2016].

GT9/GT8-SC36/AENOR (2008). Perfil de Aplicación LOM-ES V.1.0, pp. 1-62. Recuperado de http://www.educaplus.org/documentos/lom-es v1.pdf [Consulta: 25/11/2016].

Hilera González, J.R., y Hoya Marín, R. (2010). Estándares de e-learning: guía de consulta. Universidad de Alcalá. Recuperado de http://www.cc.uah.es/hilera/GuiaEstandares.pdf [Consulta: 25/11/2016].

IEEE Standard for Learning Object Metadata. (2002). IEEE Std 1484.12.1-2002, 32 p. doi: 10.1109/IEEESTD.2002.94128 Recuperado de http://ieeexplore. ieee.org/stamp/stamp.jsp?tp =\&arnumber $=1032843$ \&isnumber $=22180$ [Consulta: 25/11/2016].

IMS Global Learning Consortium. (2003). Learning design specification. Recuperado de http://www.imsglobal.org/learningdesign/ [Consulta: 25/11/2016].

IMS Global Learning Consortium. (2004). IMS AccessForAll Meta-data Information Model: Version 1.0 Final Specification. Recuperado de http://www.imsglobal.org/accessibility/accmdv1p0/imsaccmd_infov1p0.html [Consulta: 25/11/2016]. 
IMS Global Learning Consortium. (2004). IMS Access For All Meta-data: Best Practice and Implementation Guide, Version 1.0 Final Specification. Recuperado de http://www.imsglobal.org/accessibility/accmdv1p0/imsaccmd bestv1p0.html [Consulta: 25/11/2016].

IMS Global Learning Consortium. (2006). IMS META Learning Resource metadata specification. IMS Meta-Data Version 1.3. Recuperado de http://www.imsglobal.org/metadata/\#version1.3 [Consulta: 25/11/2016].

IMS Global Learning Consortium. (2012). IMS Global Access For All (AfA) Digital Resource Description Specification Information Model Version 3.0 Specification Public Draft 1.0. Recuperado

http://www.imsglobal.org/accessibility/afav3p0pd//AfA3p0_DRDinfoModel_v1p0pd.html [Consulta: 25/11/2016].

IMS Global Learning Consortium. (2012). IMS Global Access for All (AfA) Personal Needs \& Preferences (PNP) Specification Information Model Version 3.0 Specification Public Draft 1.0 . Recuperado de http://www.imsglobal.org/accessibility/afav3p0pd/AfA3p0 PNPinfoModel v1p0pd.html [Consulta: 25/11/2016].

IMS Global Learning Consortium. (2012). IMS Global Access for All (AfA) Primer Version 3.0 Specification Public Draft 1.0. Recuperado de http://www.imsglobal.org/accessibility/afav3p0pd/AfAv3p0 SpecPrimer v1p0pd.html [Consulta: 25/11/2016].

ISO/IEC 24751-1:2008. (2008). Information technology-Individualized adaptability and accessiblity in e-learning, education and training -Part 1: Framework and reference model. International Standard Organization, Geneve, Switzerland.

ISO/IEC 24751-2:2008. (2008). Information technology -- Individualized adaptability and accessibility in e-learning, education and training -- Part 2: Access for all personal needs and preferences for digital. International Standard Organization, Geneve, Switzerland.

ISO/IEC 24751-3:2008. (2008). Information technology --Individualized adaptability and acces-sibility in e-learning, education and training --Part 3: Access for all" digital resource description. International Standard Organization, Geneve, Switzerland.

JISC CETIS (2012). Into the wild: Technology for open educational resources, Reflections on three years of the UK OER Programme. University of Bolton

MILOS (s.f.a). Infraestrutura multiagentes para suporte a objetos de aprendizagem OBAA. Recuperado de http://obaa.unisinos.br/padrao metadados.htm [Consulta: 25/11/2016].

MILOS (s.f.b). Infraestrutura multiagentes para suporte objetos de aprendizagem OBAA. Infra estrutura de agentes. Recuperado de http://obaa.unisinos.br/projetomilos.htm [Consulta: 25/11/2016].

OBAA. Padrón OBAA-mapa mental. Recuperado de http://www.portalobaa.org/padraoobaa/OBAA-v2.mm/view [Consulta: 25/11/2016] 
Perfil de aplicación LOM-ES V1.0: Anexo VII. Taxonomía accesibilidad. Recuperado de http://educalab.es/documents/10180/40863/LOM-ESejemplo7.pdf/3794e5cf-a2ed-4917a1bd-193d36e00c6b [Consulta: 25/11/2016].

Perfil de aplicación LOM-ES V1.0: Etiquetado estándar de objetos digitales educativos (ODE), España. Instituto Nacional de Tecnologías Educativas y de formación del profesorado (INTEF) (2009). Recuperado de http://educalab.es/intef/tecnologia/recursosdigitales/lom-es/guia [Consulta: 25/11/2016].

Poslad, S. (2007). Specifying Protocols for Multi-Agent Systems Interaction. ACM transactions on autonomous and adaptative systems, 12(4), article 15. Recuperado de http://www.fipa.org/subgroups/ROFS-SG-docs/2007-TAAS-specifying-MAS.pdf [Consulta: 25/11/2016].

Proyecto ESVIAL: Educación Superior Virtual Inclusiva - América Latina. (2013). Guía metodológica para la implantación de desarrollos curriculares virtuales accesibles, pp. 1153. Servicio de Publicaciones de la Universidad de Alcalá, España. Recuperado de http://www.esvial.org/guia/ [Consulta: 25/11/2016]. 